\title{
Igualdade e Diferença: reflexões no âmbito do direito educacional das pessoas com deficiência.
}

\author{
Equality and Difference: reflections on the educational right of people with \\ disabilities.
}

Rosileide de Jesus de Souza Melo ${ }^{1 *}$, Alexandre Augusto Cals e Souza ${ }^{2}$

\begin{abstract}
RESUMO
Neste trabalho, pretendemos discutir algumas ideias que consideramos relevantes para a política pública inclusiva e que diz respeito à importância que questões relativas à igualdade e diferença têm adquirido para a compreensão dos processos e práticas inclusivas. Tendo como objetivo analisar como se dá as questões acerca da percepção de igualdade e diferenças no âmbito do direito das pessoas com deficiência. O interesse em pesquisar a temática surgiu da necessidade de reconhecermos os outros como pessoas de direitos em sua igualdade e em suas diferenças. A pesquisa segue uma abordagem qualitativa de cunho bibliográfico que adotou como referencial os estudos de Santos (2015), Barros (2018) e Silva (2000). Compreender aquilo que distingue igualdade e diferença é crucial para uma sociedade mais igualitária, conforme discutiuse neste trabalho, um estudo mais sistemático das relações e possíveis interações entre igualdade e diferença no tocante aos direitos dos sujeitos nos vários meios sociais e tempos históricos.
\end{abstract}

Palavras-chave: Diferença; Igualdade; Política Pública; Pessoas com Deficiência.

\section{ABSTRACT}

In this work, we intend to discuss some ideas that we consider relevant for inclusive public policy and that concerns the importance that issues related to equality and difference have acquired for the understanding of inclusive processes and practices. Aiming to analyze how the issues about the perception of equality and differences in the scope of the rights of people with disabilities occur. The interest in researching the theme arose from the need to recognize others as people with rights in their equality and in their differences. The research follows a qualitative bibliographic approach that adopted the studies by Santos (2015), Barros (2018) and Silva (2000) as a reference. Understanding what distinguishes equality and difference is crucial for a more egalitarian society, as discussed in this paper, a more systematic study of the relationships and possible interactions between equality and difference regarding the rights of subjects in various social environments and historical times.

Keywords: Difference; Equality; Public Policy; Disabled people.

\footnotetext{
${ }^{1}$ Universidade Federal do Pará- UFPA.

*E-mail: alexandre@ufpa.br
} 


\title{
INTRODUÇÃO
}

O presente trabalho intitulado: "Igualdade e Diferença: Uma questão de direitos" traz ideias relevantes para a educação especial inclusiva e que diz respeito à importância que questões relativas à igualdade e diferença têm adquirido para a compreensão dos processos e práticas inclusivas. Tendo como questão central de investigação analisar como se dá as questões acerca da percepção de igualdade e diferenças e os direitos inerentes aos sujeitos pela sociedade.

A opção pela temática em questão decorre de experiências profissionais, uma vez que percebemos que há a necessidade de problematizar a igualdade e diferença como princípio para a efetiva consolidação da educação especial inclusiva. Outros fatores de interesse foi contribuir com questões políticas e sociais tão importante e necessária relacionada ao reconhecimento dos direitos de cada indivíduo enquanto sujeitos sociais, participando, assim, enquanto sujeito das transformações socioculturais e políticas que aqui se processam, em especial no que diz respeito ao tema abordado. Mantoan (2005), discorre que:

\begin{abstract}
A inclusão escolar envolve, basicamente, uma mudança de atitude face ao Outro: que não é mais um, um indivíduo qualquer, com o qual topamos simplesmente na nossa existência e com o qual convivemos um certo tempo, maior ou menor, de nossas vidas. O Outro é alguém que é essencial para a nossa constituição como pessoa e dessa Alteridade é que subsistimos, e é dela que emana a Justiça, a garantia da vida compartilhada. (MANTOAN, 2005, p.81).
\end{abstract}

Sabe-se que vivemos em um meio social marcado pelas diferenças, seja, pela característica fisiológica, de gênero, idade ou por seu grupo de pertencimento, é a diferença que identifica cada um, diferenças que às vezes, não conseguimos evitar. A qual se apresenta em dois caminhos distintos, um caminho "pode ser construído negativamente por meio da exclusão ou da marginalização daquelas pessoas que são definidas como “outros"(WOODWARD, 2009, p.50), ou por outro caminho onde "ela pode ser celebrada como fonte de diversidade, heterogeneidade e hibridismo, sendo vista como enriquecedora" (WOODWARD, 2009, p.50). Percorremos o caminho pelo qual o sujeito é visto, em toda a sua totalidade, em sua especificidade, como um ser único, de direito em sua diferença como discute-se nos tópicos a seguir. 
Assim, procuramos direcionar os olhares às questões acerca dos direitos dos sujeitos na sociedade e a percepção que esta possui sobre esta temática, procurando o desafio de estudá-la buscando estabelecer a conexão entre os aspectos de natureza teórica e os de natureza empírica reconhecendo que esta não se constitui uma tarefa fácil haja vista a complexidade do tema abordado onde se debatem diferentes pontos de vistas. Dessa maneira, este trabalho apresenta conceitos de direito, igualdade e diferença, buscando focalizar nas questões referentes aos direitos.

Nosso objetivo neste trabalho é analisar como se dá as questões acerca da percepção de igualdade e diferenças no âmbito do direito das pessoas com deficiência.

Buscou-se aporte teórico nas contribuições de autores como: Barros (2018), Santos(2015), Silva (2000) entre outros. Seguindo uma abordagem de pesquisa qualitativa alicerçada pelo estudo bibliográfico questionamentos segundo Marconi \& Lakatos (2011), permite que o pesquisador disponha de meios para definir e solucionar, não somente questões conhecidas, como possibilita descobertas em diversas áreas onde permeia aquela problemática, podendo utilizá-la para confirmar, confrontar ou enriquecer suas proposições.

\section{IGUALDADE E DIFERENÇA}

José D’Assunção Barros em seu artigo intitulado "Igualdade e diferença: uma discussão conceitual mediada pelo contraponto das desigualdades", nos apresenta que as diferenças são marcadas pela: "nacionalidades, etnias, gêneros, faixas etárias, religiosidade, especificidades corporais, entre inúmeras outras” (BARROS, 2018). Entretanto, essas diferenças são percebidas quando em contato com o outro, é na relação com o outro que os elementos da diferença são nitidamente notados.

Nesse processo, o corpo enquanto estrutura física em movimento e em interação dialógica é um dos locais que se apresenta no estabelecimento das diferenças, pois é o corpo que marca a deficiência física, motora, sensorial, é o corpo que nos revela e revela o outro.

Dessa forma, a diferença, se apresenta, sendo o que o outro é - ele é negro, ele é religioso, ele é deficiente, como nos afirma Silva (2000), "é o que está sempre no outro". Contudo, as diferenças não são formas fixas que compõe o indivíduo, são mutáveis, de acordo com a influência do contexto social, das mudanças históricas, da tecnológica, do mundo da cultura entre outros elementos. 
Reconhecer as diferenças a partir do outro, possibilita aos indivíduos reconhecerse marcamos dessa forma a identidade, assim, a identidade é marcada pelo "quem eu sou" (SILVA, 2000). O direito de autoafirmação de quem sou é a forma mais sensata de respeito as diferenças, pois, se auto reconhecendo você também se percebe diferente dos outros.

Conviver harmonicamente com as diferenças é um ato de respeito a si mesmo e posteriormente ao outro, pois as diferenças são quase impossíveis de serem homogeneizadas (BARROS, 2018). Pois, podem haver pessoas, com a mesma nacionalidade, mesmo gênero, mas com faixas etárias diferentes, podem haver pessoas, com a mesma religiosidade, mesmo gênero, mas com especificidade corporal diferente. Enfim, homogeneizar não pode mais ser o discurso dominante.

Lennard Davis em seu artigo "Constructing Normalcy: The disabled body in the nineteenth century", o autor trata sobre a normatização dos indivíduos, a qual também perpassa pela diferença,

Nós vivemos em um mundo de normalizações. Cada um de nós se esforça para ser normal ou tenta deliberadamente evitar o estado contrário[...] Nossas crianças são classificadas na escola e testadas para determinar onde se justam em uma curva normal de aprendizagem, de inteligência. (DAVIS, 2006, p.03)

Normalizar, seguir um padrão parece ser o que se quer das minorias principalmente na modernidade onde o ser humano é dotado de um modelo a ser seguido, seja pela altura, pelo peso, pela cor da pele, pela deficiência do corpo. Tudo é controlado, pois se entende que os corpos ideias são mais saudáveis, se desenvolvem melhor intelectualmente. Pensamos que essas justificativas são apenas discursos para omitir a sociedade a qual vivemos, uma sociedade opressora, excludente, desigual, preconceituosa e autoritária.

Os grupos minoritários, e especificamente o grupo das pessoas com deficiência (PcD)) por conta "dos padrões normalizadores passaram a ser excluídos, por nascerem com ou por adquirirem uma lesão" (BENTES, p.37, 2012). Por isso, como forma de reivindicar por direitos grupos minoritários expressam as suas diferenças como modo de resistência e lutam para assegurar o direito aos bens sociais. Silva $(2009$, p. 81), afirma 
que, “[...] a enunciação da diferença traduzem o desejo dos diferentes grupos sociais, assimetricamente situados, de garantir o acesso privilegiado aos bens sociais. [...]".

As pessoas com deficiência historicamente, foram hierarquizados, considerados inferiores ao grupo das pessoas sem deficiência, não são vistas como uma pessoa normal seu corpo é julgado, por isso, lutam para terem acesso aos bens coletivos da sociedade. Neste caso, vemos a marcação da diferença tanto por meio de representação de um grupo, quanto por meio de formas de exclusão social. Pois o discurso da diferença é uma discussão que busca na verdade padrões de normalidades, que muitas vezes são impostos. Dessa forma não sendo levado em consideração o ser do indivíduo.

Bentes (2012) ressalta que se alguém com deficiência consegue adentrar aos grupos que estão dentro da normalidade, mesmo assim ainda serão menosprezados ou tratados como invisíveis, ou seja desconsideram sua existência, suas necessidades. $\mathrm{O}$ referido autor ressalta que o corpo com deficiência é menosprezado é invisibilizado, as diferenças presentes nos deficientes não são reconhecidas. "Na invisibilidade, o corpo do "outro", deficiente não é notado, não e trazido à consciência"

As diferenças ocasionadas pela sua condição física, social, cultural entre outras convergem na relação de incluir e excluir, e se traduz assim, em declarações sobre quem pertence e quem não pertence, sobre quem está incluído e quem está excluído (SILVA, 2009). Dessa forma, criou-se uma divisão social entre eu e o outro. Quem está no padrão, está incluído é pertencente, quem não está no padrão automaticamente está excluído.

Esta divisão é presente nos discursos das pessoas, como: ele é deficiente, ele é negro, ele é homossexual. São discursos utilizados como uma necessidade de enfatizar que eles se diferem por terem suas diferenças. Percebe-se a necessidade de demarcar as pessoas, de separar, de classificá-las, como se fossem objetos. Nessa perspectiva, a palavra diferente aparece sempre associada à ideia de superior X inferior, de um sistema que classifica mais ao mesmo tempo exclui.

Na exclusão não se leva em consideração as diferenças culturais dos sujeitos, talvez a efetivação dos direitos culturais possibilitasse a ruptura de paradigmas construídos para incluir e excluir. Meyer-Bisch (2011), diz que os direitos culturais,

podem ser definidos como os direitos de uma pessoa, sozinha ou coletivamente, de exercer livremente atividades culturais para vivenciar seu processo nunca acabado de identificação, o que implica o direito de aceder aos recursos necessários para isso. (p.28). 
Ter a garantia dos direitos culturais proporciona à proteção das diferenças da qual se faz presente na coletividade. Tornando-se o "reconhecimento de diferenças como elemento de realização do princípio da igualdade" (SANTOS, 2009, p. 77). Assim, nos tornaríamos iguais em direitos culturais. Igualdade que,

deverá compreender a totalidade dos direitos que têm a ver com os processos culturais: as liberdades de criação artística, científica e de comunicação cultural, os direitos autorais, o direito de acesso à cultura, o direito à identidade e à diferença cultural, o direito à conservação do patrimônio cultural. (PEDRO, 2011, p. 45).

É, neste contexto, que a diferença cultural assume um papel muito importante na formação dos sujeitos. Pois este passa a ser reconhecido em sua totalidade, não de acordo com as expectativas coletivas de padronização cultural. A luta por direitos a diferença não é um debate atual deste século, Santos e Lucas (2015) sinalizam que historicamente essas lutam tiveram início,

A partir da década de sessenta do século passado, com a agudização de lutas políticas por diferentes grupos que compunham as sociedades multifacetadas dos países do norte, passaram a ocorrer reações culturais, comportamentais, políticas e filosóficas voltadas a propor noções mais inclusivas e, simultaneamente, respeitadoras da diversidade de concepções alternativas da dignidade humana [...]. (SANTOS E LUCAS 2015, p. 47).

Em prol de direitos assim como negros, mulheres, homossexuais, as pessoas com deficiência faziam movimentos de resistência. Assim, os grupos se estruturavam, a fim de conquistar o direito de ser diferente, pois afinal, "o que todos esses grupos tinham em comum era a necessidade de reconhecimento de suas diferenças socioculturais" (SANTOS E LUCAS, 2015, p. 49). Eles precisavam buscar o reconhecimento de seus direitos através de lutas, no caso das pessoas com deficiência, essa luta engloba além deles, familiares, amigos e ativista pela causa.

Gleeson (1999), enfatiza que os movimentos das pessoas com deficiência surgiram nos anos de 1950 e 1960, com discursões sobre os direitos políticos, civis sobretudo do direito ao trabalho, aos benefícios de segurança social e de acesso as instituições públicas e privadas.

Neste sentido, a luta por direitos das pessoas com deficiência resgata um vínculo necessário com os direitos humanos e com a globalização, como infere o professor Boaventura de Souza Santos: 
A complexidade dos Direitos Humanos reside em que eles podem ser concebidos e praticados, quer como forma de localismo globalizado, quer como forma de cosmopolitismo ou, por outras palavras, quer como globalização hegemônica, quer como globalização contra-hegemônica. [...]. A minha tese é que, enquanto forem concebidos como direitos humanos universais, os Direitos Humanos tenderão a operar como localismo globalizado e, portanto, como forma de globalização hegemônica. Para poder operar como forma de cosmopolitismo, como globalização contra-hegemônica, os Direitos Humanos têm de ser reconceitualizados [...]. (SANTOS, 2009, p. 13).

Entendemos dessa forma, que o autor nos coloca que os direitos humanos em um mundo globalizado devem ser repensados, em uma perspectiva que veja o indivíduo do local para o global. Pois, "a globalização, tal como a quer o neoliberalismo, está associada à exclusão social" (SILVA, 2000, p. 115), fato que contribui para a intensificação do desrespeito dos direitos humanos, em uma forma de globalização hegemônica. Por isso, os direitos atenderão as minorias, de forma contra hegemônica, se partirem do local.

A diferença percebida do local é fonte para a preservação da diversidade, mas sempre há uma pressão para que as pessoas sejam como aquelas que ditam as normas hegemônicas, o que ocasiona um processo de hierarquização das igualdades e diferenças (SILVA, 2000). Em uma luta contra hegemônica visando a valorização, o reconhecimento, e a emancipação dos sujeitos, Boaventura de Sousa Santos, enfatiza que:

Muitas pessoas e organizações não governamentais têm lutado pelos Direitos Humanos, correndo riscos em defesa de grupos oprimidos vitimizados por Estados autoritários, por práticas econômicas excludentes [...] Creio que a tarefa central da política emancipatória do nosso tempo consiste em transformar a conceitualização e a prática dos Direitos Humanos, de um localismo globalizado num projeto cosmopolita. (SANTOS, 2009, p. 14).

O cosmopolitismo é exemplo de heterogeneidade dos movimentos e organizações que lutam em uma perspectiva contra-hegemônica, frente a exclusão causada pela globalização. A exclusão ocorre porque infelizmente as pessoas são vistas em uma perspectiva que não se reconhece a diferença. Assim, a sociedade passa a ver a diferença como um problema. Dando-se mais importância ao discurso homogeneizador que é forte, o que provoca uma divulgação ou busca por corpos ideiais, que em termos históricos, sociais e políticos, nada tem a ver com a forma pela qual o grupo se vê ou se representa. Tornando a busca, por direitos sociais uma arena de conflitos entre indivíduos e entre grupos sociais, uma vez que a busca por poder está presente nas relações. 
O ser humano apresenta diferenças, mas também apresenta igualdade, não significa que tudo é igual, ou que tudo seja diferente. Na Constituição Federal de 1988 a igualdade se refere aos direitos dos indivíduos, direitos que diz respeitos a todos, devendo haver, equiparação ao gozo e fruição de direitos. De acordo com a constituição, há uma igualdade jurídica, econômica, social e política, ser diferente não implica em ter menos direito. A igualdade está correlacionada com a diferença na implantação das justiças sociais. Ambas se relacionam horizontalmente, caminham lado a lado. (BARROS, 2018). Contudo, a dialética entre o direito à igualdade e o direito à diferença não é uma relação simples. Isso porque de um lado, a igualdade se apresenta e deve ser pensado como princípio de cidadania, da sociedade moderna, sendo vista também como um princípio para que as pessoas não sejam discriminadas.

A igualdade só existe a partir do momento que se reconhece as diferenças, isso porque ser reconhecido em sua especificidade não gera distinções sobre estar ou não no patrão, reconhecer as diferenças liberta o indivíduo da homogeneização. Assim, a "absolutização das diferenças opera segundo a norma do relativismo que torna incomparáveis as diferenças”. (SANTOS, 2009, p. 15).

Por isso, reconhecer as diferenças e reconhecer o direito à diferença é o passo inicial para desconstruir instituições educacionais segregadora, excludente, normativa e elitista. Não é uma tarefa fácil, sendo que reverbera o conflito entre o pensamento utópico e o distópico, pois "o horizonte utópico tende a produzir a valorização das diferenças", enquanto "o horizonte distópico introduz a perspectiva da eliminação ou opressão das diferenças" (Barros, 2018). O que não deve haver nas escolas é pensamento distópico, haja vista que eliminar uma diferença é muito difícil ou quase impossível, na verdade seria um absurdo pensar em um igualitarismo, uma igualdade padronizada para todos. Acreditamos que as diferenças sendo valorizadas e reconhecidas é o caminho mais exitoso para a inclusão.

Barros (2018, p.18) reitera que existe uma distinção entre igualdade e diferença, "temos algo da ordem das modalidades de ser: uma coisa ou é igual à outra, pelo menos em determinado aspecto, ou então dela difere". Em um grupo de pessoas, podemos considerar sua igualdade ou diferença em relação ao aspecto sexual, ao aspecto profissional, ao aspecto étnico, e assim por diante. Percebemos que têm elementos que nos difere e há elementos que nos iguala. As pessoas não precisam ser iguais, pois, o igualitarismo corro e a alma e a diferença dar um status de pertencimento a coletividade 
"é preciso que tenhamos o direito de sermos diferentes quando a igualdade nos descaracteriza e o direito de sermos iguais quando a diferença nos inferioriza". (SANTOS, 2009, p.36-37).

Neste debate é importante ressaltarmos que a diferença também pode ser entendida como desigualdade, comparando os grupos, para atender a determinados projetos sociais de dominação. Como por exemplo a oposição entre pessoas sem deficiência e pessoas com deficiência, surdos e ouvintes, a qual deve ser necessariamente compreendida como um contraste entre duas diferenças. A diferença neste sentido é percebida como desigual, de forma que os grupos sem deficiência, têm mais, acesso ao mercado de trabalho, tem um nível mais elevado de escolarização, compatibilidade entre série e idade.

As construções históricas das diferenças se dão no meio social, as quais em determinado período se apresenta de duas maneiras. Por um lado, existe uma construção social "externa" das diferenças; por outro, existe uma construção social "interna" dessas mesmas diferenças (BARROS, 2018). A sociedade decide, na construção externa, que diferenças serão consideradas relevantes para compor o quadro mais geral das diferenças socialmente percebidas. Ao mesmo tempo, cada uma das diferenças também é construída internamente considerando diversas perspectivas, e essa construção é constantemente recontextualizada.

$\mathrm{Na}$ atualidade, as diferenças dos alunos com deficiência, é vista negativamente pelas pessoas, pois ter uma deficiência passa a ser entendida como desigualdade, sendo materializada em injustiças sócias (MELO, 2015). Isso mostra a não aceitação das diferenças, o que suscita o fenômeno da exclusão, muito presente na educação brasileira. Uma exclusão que ocorre pela aspiração de enquadrar os sujeitos que não estão nos padrões da escola e da sociedade. Sem levar em consideração as especificidades do outro, como: pertencimento étnico, diferenças etárias, de gênero, religiosa, financeira e etc., ou seja, as diferenças são transformadas em desigualdades. (CAUDOROR, 2007).

Nessa discussão sobre aceitar as diferenças das pessoas com deficiência é que se situam os estudos socioculturais da deficiência, o qual falar sobre a anormalidade como aspecto teórico que provoca a diferença, a discriminação e a própria inclusão (BENTES, 2015, p.42). Na busca por uma inclusão para todos é necessário se pensar em uma teoria que respeite as diferenças, 
Nessa teoria, a pessoa deficiente, o surdo, particularmente e peça fundamental, mas não e só ele, as outras deficiências precisam ser explicitadas, precisam ser vistas. Esta nova forma de ver será chamada aqui de abordagem sociocultural da deficiência. (BENTES, p.42, 2015).

Em uma visão sociocultural, a deficiência não é um problema para o indivíduo, é a sociedade que coloca barreiras, limita e acha um problema, outros corpos serem deficientes. Talvez seja por isso que, um dos teóricos do disability study (estudo sobre deficiências), no Estados Unidos, Alberley(1991), enfatiza que os deficientes são oprimidos pela sociedade, isso porque a sociedade é moldada para atender e conviver com as pessoas sem deficiência.

Dessa forma seria a sociedade que deixaria de lado princípios de convivência harmoniosa com as suas diferenças. A falta de respeito as diferenças resultam em incapacitar e impor a deficiência. Seria necessário remover barreiras e estabelecer legislação que contemple a pessoa com deficiência para que possa ter direitos sociais garantidos.

A educação especial inclusiva está inserida num contexto multicultural, onde a escola deve atender os diferentes grupos sociais que apresentam diferenças físicosensoriais e cognitivas, das pessoas surdas, cegas, cadeirantes, pessoas com síndrome, ou pessoas com lesão. É a partir do momento que se reconhece a diferença do aluno que se passa a entender de fato, que a inclusão educacional, prevê um ambiente heterogêneo, sendo que a "prática da inclusão se baseia em princípios diversos, tais como: aceitação das diferenças individuais, valorização de cada indivíduo e convivência dentro da diversidade e cooperação". (SILVA E MARTINS, 2007, p. 73).

Assim, é notório que a educação especial inclusiva só é possível a partir do respeito às diferenças socioculturais, pois quando o professor aceita e respeita as diferenças, ele aceita a inclusão, desenvolve trabalhos levando em consideração as especificidades do aluno e não buscando a igualdade como produto final da aprendizagem. A perspectiva inclusiva ver, as diferenças não como problemas, mas como possibilidade. Neste sentido, os estudiosos Gaio e Porto relatam que:

As diferenças, hoje, devem ser encaradas como positivas e de fundamental importância na construção da identidade social dos seres humanos, pois é fator muito significativo para uma vida de respeito, aceitação, acolhimento, companheirismo, solidariedade e reconhecimento. (GAIO E PORTO, 2006, p. 14). 
Carvalho (2005), advoga uma Educação Inclusiva, alicerçada na ideia de que com a inclusão, as diferenças não são vistas como problemas, mas como diversidade. De forma, que a escola comum se torna inclusiva quando reconhece as diferenças dos alunos diante do processo educativo e busca a participação e o progresso de todos, adotando novas práticas pedagógicas, removendo as barreiras na aprendizagem, sejam elas internas ou externas aos alunos, ofertando todas as formas de acessibilidade, seja arquitetônica, atitudinal, metodológica ou linguística para alcançar o ensino.

A educação especial inclusiva não deve ser realizada de forma que os alunos com deficiência devam se encaixar nas regras de padronização, infelizmente ainda há instituições escolares que trazem consigo o pensamento de que todos precisam estar dentro de um padrão de normalidade. Mendes (2002) ressalta a importância da educação inclusiva no sistema educacional, a qual tem práticas e pressupostos bem definidas, fundamentado na concepção de direitos humanos, que conjuga igualdade e diferença como valores indissociáveis. Assim, reconhecer a diferença é crucial no processo educativo para não termos salas de aulas discriminatórias, e para além, entender que, diferença e igualdade caminham juntas, não adianta afirmar a diferença se eu não afirmo e não reconheço a igualdade. Uma política de igualdade que nega as diferenças é excludente.

Dessa forma, entendemos que lutar pela igualdade obscurece as diferenças, homogeneizando os sujeitos coletivos. Almejar homogeneizar as pessoas é algo negativo, tem uma carga autoritária, significa sobretudo, tirar-lhes, elementos que lhe constitui enquanto sujeito. Precisamos de um contexto social de igualdade onde os indivíduos sejam respeitados em suas especificidades, em suas diferenças, sendo detentor de direitos como qualquer outro cidadão.

\section{CONSIDERAÇÕES FINAIS}

A questão da Diferença e Igualdade na sociedade envolve inúmeros fatores e aspectos que não podem ser discutidos nos limites deste trabalho. Contudo, o mesmo buscou mostrar que as análises, acerca das questões que envolvem os direitos dos sujeitos sociais deve partir, antes de mais nada, de uma compreensão muito clara e precisa sobre o que é e quais são propriamente os direitos que cabem aos cidadãos - nos sentidos

filosófico, sociológico, antropológico, histórico, humano, etc. Também temos a questão 
das diferenças e das lutas pela afirmação das diferenças, ao lado do combate às desigualdades sociais que se entrelaçam com determinadas diferenças, sejam étnicas, etárias, sexuais, entre outras.

Na luta por garantia de direitos a igualdade é entendida como uma orientação pelo qual as pessoas pleiteiam para reduzir e eliminar as diferenças discriminatórias. A defesa das diferenças não permanece se há a negação da igualdade. Em razão disso, a pessoa humana em quem o princípio de igualdade deve se aplicar sem discriminações, acaba sendo discriminado. Por isso, os Estados democráticos de direito são peças importantes pois, zelam em assinalar as discriminações que devem ser sempre proibidas sejam pela: origem, raça, sexo, religião, cor, crença.

Ao mesmo tempo, seria absurdo pensar um igualitarismo, uma igualdade absoluta, de modo a impor uniformemente as leis sobre todos os sujeitos e em todas as situações. Um tratamento diferenciado só se justifica perante uma situação objetiva e racional e cuja aplicação considere o contexto mais amplo. A diferença de tratamento deve estar relacionada com o objeto e com a finalidade da lei e ser suficientemente clara e lógica para a justificar

Por isso, compreender aquilo que distingue Igualdade e diferença é crucial para uma sociedade mais igualitária. Conforme discutiu-se neste trabalho, um estudo mais sistemático das relações e possíveis interações entre Igualdade e diferença no tocante aos direitos dos sujeitos nos vários meios sociais e tempos históricos - e em âmbitos tão diversos como sexualidade, nacionalidade, etnia, religião, educação - podem permitir que se compreenda melhor como os sistemas de dominação, os mais sutis ou os mais explicitamente cruéis, valem-se frequentemente de deslocamentos diversos entre os âmbitos da desigualdade e da diferença, forçando a leitura de um como se fosse o outro, de modo que possa melhor exercer a dominação.

Assim, as relações entre Igualdades e diferenças emergem aqui como um verdadeiro campo de estudos, clamando por conceitos e metodologias próprias e abrindo caminho a novas análises e investigações. 


\section{REFERÊNCIAS}

ABBERLEY, P. Disabled People: Three Theories of Abnormality. Bristol Polytechnic Department of Economics \& Social Science. 1991. Disponível em: https://disabilitystudies.leeds.ac.uk/wp-content/uploads/sites/40/library/Abberley-th-abnormality.pdf. Acesso em: 11 de janeiro de 2020.

BARROS, Diana Luz Pessoa de. O discurso intolerante: primeiros estudos. Disponível em: http://www. rumoatolerancia.fflch.usp.br/node/2186.

BENTES, José Anchieta de Oliveira. Normalidade e disnormalidade: formas de trabalho docente na educação de surdos. / José Anchieta de Oliveira Bentes, Maria Cristina Piumbato Innocentini Hayashi. Campina Grande: EDUEPB, 2012.

CARVALHO, Rosita Edler. Educação Inclusiva: com os pingos nos "is". (Porto Alegre: Editora Mediação, 2005.

DAVIS, L. J. Constructing normalcy: the Bell curve, the Bell curve, the novel, and the invention of the disabled body in the nineteenth century. In: disability studies reader. 2nd ed. New York: Routledge, 2006a, p. 3- 16. (Ed). The

GAIO, R.; PORTO, E. Educação Física e pedagogia do movimento: possibilidades do corpo em diálogo com as diferenças. In: DE MARCO, A. (Org.). Educação

Física: cultura e sociedade. Campinas: Papirus, 2006.

MANTOAN, Maria. T. Eglér. Inclusão escolar: o que é? Por quê? Como fazer? São Paulo: Moderna, 2005 - Coleção cotidiano escolar.

MARCONI, Marina de Andrade; LAKATOS, Eva Maria. Metodologia do Trabalho Cientifico. São Paulo, $3^{\text {a }}$ ed., 2011.

MENDES, E. G. Perspectivas para construção da escola inclusiva no Brasil. In: PALHARES, M. S.; MARINS, E. S. C. F. (Org.) Escola Inclusiva. São Carlos: EduFSCar, 2002. p. 61-85.

MEYER-BISCH, Patrice. A centralidade dos direitos culturais, pontos de contato entre diversidade e direitos humanos. In: Revista Observatório Itaú Cultural / n. 11 (jan./abr. 2011). São Paulo: Itaú Cultural, 2011.

PEDRO, Jesús de. Direitos Culturais, o filho pródigo dos direitos humanos. Revista Observatório Itaú Cultural / OIC - n. 11 (jan./abr. 2011). São Paulo, SP: Itaú Cultural, 2011. Disponível em: Acesso em: 15 janeiro. 2020.

SANTOS, André Leonardo Copetti; LUCAS, Douglas César. A (in)diferença no direito. Porto Alegre. Livraria do Advogado, 2015.

SANTOS, Boaventura de Sousa. Direitos Humanos: o desafio da interculturalidade. Revista de Direitos Humanos, Brasília, n. 2, p. 10-18, jun. 2009. Disponível em: . Acesso em: 14 de agosto de 2018. 

2006.

A Gramática do Tempo: para uma nova cultura política. São Paulo: Cortez,

SEVERINO. Antônio Joaquim. O Trabalho Científico - da epistemologia à técnica. $23^{\mathrm{a}}$ edição - revista e atualizada. Editora Cortez: 2007.

SILVA, Tomaz T. da. A produção social da identidade e da diferença. In: SILVA, Tomaz T. da (Org.) Identidade e diferença: a perspectiva dos Estudos Culturais. Petrópolis: Vozes, 2006, p. 73-102.

A produção social da identidade e da diferença. In: SILVA, Tomaz Tadeu (org. e trad.). Identidade e diferença: a perspectiva dos estudos culturais. Petrópolis: Vozes, 2000 .

A produção social da identidade e da diferença. In: SILVA, Tomaz Tadeu da (org.). Identidades e diferenças: a perspectiva dos Estudos Culturais. Petrópolis, RJ: Vozes, 2000.

WOODWARD, Kathryn. Identidade e diferença: uma introdução teórica e conceitual. In: SILVA, Tomaz T. da (Org.) Identidade e diferença: a perspectiva dos Estudos Culturais. Petrópolis: Vozes, 2006, p. 07-72. 